\title{
Online Appendix to \\ The Exchange Rate Response to Monetary Policy Innovations
}

\author{
Viktoria Hnatkovska*, Amartya Lahiri ${ }^{\dagger}$, and Carlos A. Vegh ${ }^{\dagger}$
}

September 2, 2015

\section{Adding a non-traded good to the model}

Consider a simple extension of the model to include non-traded goods. The presence of non-traded goods allows for systematic deviations from PPP. Suppose the utility function is defined over aggregate consumption, as before, where aggregate consumption is a function of traded and non-traded consumption. Then, the aggregate price index $P$ is a function of traded and non-traded goods prices, $P_{t}=\omega\left(P_{t}^{T}, P_{t}^{N}\right)$, where $\omega($ ) is an increasing function of $P_{t}^{T}$ and $P_{t}^{N}$ and is homogeneous of degree one. $P_{t}^{T}$ and $P_{t}^{N}$ are the domestic prices of tradable and nontradable goods. Also let $P_{t}^{T *}$ and $P_{t}^{N *}$ denote their foreign country equivalents. For traded goods, the law of one price holds, i.e. $P_{t}^{T}=E_{t} P_{t}^{T *}$. Let's normalize $P_{t}^{T *}=1$. The nominal exchange rate is then given by

$$
\begin{aligned}
E_{t} & =P_{t}^{T}=P_{t} \frac{P_{t}^{T}}{P_{t}} \\
& =P_{t} \frac{P_{t}^{T}}{\omega\left(P_{t}^{T}, P_{t}^{N}\right)} \\
& =P_{t} \frac{1}{\omega\left(1, P_{t}^{N} / P_{t}^{T}\right)} .
\end{aligned}
$$

Here $1 / \omega\left(1, P_{t}^{N} / P_{t}^{T}\right)=q_{t}$ is the real exchange rate. In this example, the real exchange rate is solely a function of the relative price of non-traded goods. The price level is determined from the money market equilibrium condition $\frac{M_{t}}{P_{t}}=L\left(i_{t+1}, i_{t+1}^{g}\right)$, where $M_{t}$ is nominal money supply in terms of domestic currency, and $L$ is real money demand defined in terms of the aggregate consumption good. Substituting this into the

\footnotetext{
*Department of Economics, University of British Columbia, 997 - 1873 East Mall, Vancouver, BC V6T 1Z1, Canada. E-mail addresses: Viktoriya.Hnatkovska@ubc.ca (Hnatkovska), Amartya.Lahiri@ubc.ca (Lahiri).

${ }^{\dagger}$ Department of International Economics, Johns Hopkins SAIS, Nitze Building, 1740 Massachusetts Ave., N.W. Washington, D.C. 20036, USA and NBER. E-mail address: cvegh1@jhu.edu
} 
expression for the nominal exchange rate gives

$$
E_{t}=\frac{M_{t}}{L\left(i_{t+1} i_{t+1}^{g}\right)} q_{t} .
$$

Note that money demand can be written as $L\left(i_{t+1}, i_{t+1}^{g}\right)=L\left(i_{t+1}, i_{t+1}^{g}\right)\left(P_{t} / P_{t}^{T}\right)\left(P_{t}^{T} / P_{t}\right)=\hat{L}\left(i_{t+1}, i_{t+1}^{g}\right)\left(P_{t}^{T} / P_{t}\right)=$ $\hat{L}\left(i_{t+1}, i_{t+1}^{g}\right) q_{t}$. Here $\hat{L}\left(i_{t+1} i_{t+1}^{g}\right)$ is real money demand denominated in terms of traded goods, which is what we have in the model. This allows us to re-write the expression for the nominal exchange rate as

$$
E_{t}=\frac{M_{t}}{\hat{L}\left(i_{t+1} i_{t+1}^{g}\right)}
$$

This expression implies that the nominal exchange rate is a function of nominal money supply and real money demand in terms of traded goods. This is the same expression as we have in the paper.

Next, consider the aggregate price level

$$
P_{t}=\frac{M_{t}}{L\left(i_{t+1}, i_{t+1}^{g}\right)}
$$

which in terms of traded goods becomes

$$
P_{t}=\frac{M_{t}}{\hat{L}\left(i_{t+1}, i_{t+1}^{g}\right) q_{t}}
$$

Thus, the aggregate price index is a function of nominal money supply, real money demand and the real exchange rate. This expression differs from the one in the paper by a factor $1 / q_{t}$ which is the inverse of the real exchange rate.

The preceding allows us to relate the nominal exchange rate and the price level as

$$
P_{t}=E_{t} \frac{1}{q_{t}}
$$

In the presence of non-traded goods the real exchange rate drives a wedge between the price level and the nominal exchange rate. The model's predictions for the nominal exchange rate remain unchanged, but the price level now contains the real exchange rate term. Moreover, depending on the precise specification of the model, the real exchange rate $q$ could appreciate or depreciate in response to an increase in the interest rate $i^{g}$. Hence, while the implications of a rise in $i^{g}$ on the exchange rate would stay unchanged, the predicted effect on $P$ would not. This is the reason why we consider the model in the paper to be one that develops predictions for the exchange rate and not the price level. 